\title{
The structure of sculpin populations along a stream size gradient
}

\author{
Charles S. Anderson \\ Museum of Zoology, The University of Michigan, Ann Arbor, MI 48109, U.S.A. \\ Present address: Savannah River Ecology Laboratory, Drawer E, Aiken, SC 29801, U.S.A
}

Keywords: Cottus, River continuum, Density, Growth, Fecundity, Predation, Population regulation

\section{Synopsis}

Data on spatial variation of sculpin density, growth and fecundity support the hypothesis that populations of stream fish are structured by changes in risk of predation and prey availability along a gradient in stream size. Cottus bairdi in warm streams and $C$. cognatus in cold streams exhibit similar patterns. Sculpins in large streams have faster individual growth rates and higher fecundities than those in small streams, but occur at lower density. The patterns appear to be persistent and suggest that predation reduces sculpin density in larger streams. Competitive release, variations in prey productivity, and local factors probably contribute to the variation in sculpin growth.

\section{Introduction}

This paper uses two species of Cottus to test four hypotheses about the factors controlling stream fish populations. Changes in density, growth rate and fecundity between stocks along a gradient in stream size are compared to predictions derived from four simple models.

Gorman \& Karr (1978) described stream fishes as habitat specialists. Habitat availability has been said to determine distributions within drainage systems, local diversity and density (Shelford 1911, Sheldon 1968, Stalnaker 1979). The habitat availability hypothesis proposes that habitat dependent factors regulate populations, but ignores the position of the habitat patch in a drainage. Thus it predicts that stocks approach some characteristic demographic structure within patches throughout a stream system. Population (or stock) density should be correlated with the area of a limiting microhabitat, but growth and fecundity should not change with stream size.
Horwitz (1978) proposed that environmental extremes in temporally variable small streams periodically exterminate some species. Since fish recolonize from stable downstream refugia, he predicted lower species richness in headwater locations (Whiteside \& McNatt 1972, Horwitz 1978). In a simple extirpation/recolonization model, local density is determined by time since recolonization, so upstream stocks should be at lower density and individuals there should grow faster. If headwaters are repopulated rapidly, then other factors must generally limit fish distributions and these predicted differences in density and growth will seldom be found.

A third hypothesis can be tested: biological interactions which change regularly with stream size are major determinants of local density, population structure and longitudinal distribution. The species composition of fishes and insects (a major food resource for fish) changes with stream size, so interactions with predators, competitors, or prey 
should change survivorship, growth and reproduction along a stream size gradicnt (even within similar microhabitats). Horwitz (1978) recognized that biological interactions could change with stream size, but he did not test the idea.

Small benthic fish, like sculpins, could be at greater risk in larger streams because piscivorous fish are added to the predator guild in large streams (Horwitz 1978, Schlosser 1982) or because the greater average depth and smaller average substrate size increase efficiency of fish attacking them (Ware 1972, Stein \& Magnuson 1976, Anderson 1983). Such community and habitat changes should alter the mortality schedules of many species.

Growth and fecundity should change with stream size because food availability is altered by changes in habitat complexity and prey density. Abundances of potential prey change with position in a drainage, even in physically similar habitats, because their food supply changes (Vannote et al. 1980, Alstad 1982, Minshall et al. 1983).

Each of these three models would be rejected as insufficient if there were no regular changes in density, growth or fecundity along a stream size gradient. This would occur if unique local conditions strongly influence regulatory mechanisms (a fourth hypothesis) or if there were no significant differences between stocks (the general null hypothesis). If local peculiarities limit stocks, there should be erratic variations between stocks sampled along a stream size gradient or over time.

Because sculpins are sedentary (Brown \& Downhower 1982), one would expect their population structure to be strongly influenced by local conditions, historic episodes of extirpation, or by distribution of particular habitat types, and thus provide an unusually strong test of the hypothesis that biological mechanisms of population regulation change with position in a drainage. Changes in growth and longevity between streams (Mason \& Machidori 1976) suggest local conditions are important. Sculpins nest in cavities, so they may be limited by spawning habitat distribution (Balon 1975).

I tested the four hypotheses (limitation by habitat availability, by extirpation/recolonization events, by biological interactions or by local pecu- liarities) by gathering data on sculpins from two local warmwater rivers and from the Pigeon River, a coldwater trout stream. I tried to bias my data against all three hypotheses which predict influences of stream size by pooling data from several tributaries and excluding locations where preliminary observations were made. This decreases the likelihood that any apparent correlations with stream size are simply due to unusual local habitat structure or historical perturbations. I further tested the three main hypotheses by examining sculpins in the Pigeon River where predatory trout were not restricted to the largest streams. Any demographic trends which occured with stream size in spite of these biases are taken as evidence of persistent structuring, by whichever proposed mechanism best predicts them.

\section{Methods}

To test for changes in sculpin density, growth, and fecundity with stream size, I sampled sculpins at 12 warmwater locations between 27 March and 8 April, 1980, selecting locations for ease of access, the presence of a gallery of uncut vegetation, and the existence of at least one riffle-pool sequence throughout which I could see the bottom clearly while electrofishing. In practice, I could sample areas up to $0.9 \mathrm{~m}$ deep routinely. I avoided some areas in the large streams that were too deep for the bottom to be seen clearly. Since sculpins are more concentrated in shallow water, the density estimates for large streams are biased upward. The stocks examined (Table 1) were within a region of glacial moraines where sculpins are widespread (Smith et al. 1981).

Between 28-30 April, 1981, I collected eight samples from the Pigeon River, a coldwater trout stream with unusually constant discharge (Knutilla 1967). This tested the possibility that low densities in larger warmwater streams were due to lethal summer temperatures or qualitative changes in predator composition. Pigeon River locations were selected only for stream size and ease of access since gallery vegetation was prevalent, and direct evidence of human disturbance was rare. 
Table 1. Stream width (m), sculpin density (number per $100 \mathrm{~m}^{2}$ ), area searched $\left(\mathrm{m}^{2}\right)$ at 12 warmwater and 8 coldwater locations. The Saline River is a tributary of the Raisin River, while Mill Creek, Fleming Creek, and Honey Creek are tributaries of the Huron River.

\begin{tabular}{lrrr}
\hline Location & Width & Density & Area \\
\hline Warmwater streams & & & \\
1. Raisin River & 16.0 & 3 & 960 \\
2. Mill Creek & 12.0 & 3 & 1200 \\
3. Raisin River & 8.0 & 34 & 280 \\
4. Mill Creek & 7.0 & 11 & 700 \\
5. Saline River & 6.0 & 29 & 900 \\
6. Fleming Creek & 5.0 & 79 & 250 \\
7. Raisin River & 4.0 & 72 & 100 \\
8. Honey Creek & 2.0 & 93 & 60 \\
9. Saline River & 1.5 & 133 & 75 \\
10. Honey Creek & 1.0 & 80 & 60 \\
11. Honey Creek & 0.5 & 92 & 50 \\
12. Mill Creek & 0.3 & 48 & 25 \\
Coldwater streams & & & \\
13. Pigeon River & 14.0 & 1 & 1750 \\
14. Pigeon River & 13.5 & 1 & 810 \\
15. Pigeon River & 11.0 & 3 & 1375 \\
16. Pigeon River & 8.0 & 25 & 400 \\
17. Pigeon River & 4.0 & 45 & 300 \\
18. Pigeon River & 3.0 & 14 & 225 \\
19. Pigeon River & 1.0 & 82 & 100 \\
20. Pigeon River & 0.7 & 72 & 52 \\
& & & \\
\hline
\end{tabular}

At each location I fished the area with a backpack electrofisher, working upstream from bank to bank through several riffle-pool subsections. An attempt was made to pick up every sculpin and unrecognizable fish seen using a $3 \mathrm{~mm}$ mesh dipnet. The presence of other species was noted, but I made little effort to catch them. All sculpins caught were preserved frozen for laboratory analysis.

By fishing each area only once I was able to survey more streams and longer reaches within the time available before spawning. This sacrificed some precision in estimating density, but other experiments showed the probability of capturing any one individual was consistently about 0.5 with this method.

Capture probabilities were estimated from the depletion rate (Zippin 1956) in $100 \mathrm{~m}$ long experimental sections fished two to six times, with and without block nets in place. These capture probabilities ranged from 0.40 to 0.65 with a mean of 0.55
( $n=20$; Anderson 1983). Block nets did not increase capture probabilities so they were not used in this study. A deliberate search with a low power electrofisher was effective for sculpins, but inefficient for mobile species (Mahon 1980). The electrofisher used produced two levels of constant voltage, pulsed DC output between a floating cathode and an anode probe $($ low $=100 \mathrm{~V}, 3 \mathrm{~A}$; high $=$ $200 \mathrm{~V}, 5 \mathrm{~A})$.

Width was selected as an index of stream size because it is correlated with discharge, depth, substrate size, light exposure, temperature, and other parameters which vary continuously along a stream but are more difficult to quantify (Vannote et al. 1980). The area $\left(\mathrm{m}^{2}\right)$ sampled was estimated as stream width times section length.

In the laboratory the total length of each sculpin was measured to the nearest millimeter. All mature and some immature sculpins were then towel dried and weighed to the nearest milligram. For most fish, the stomach and intestinal tract were emptied and the gonads and somatic carcass were weighed. Sagittal otoliths were examined from individuals which could not be aged from length frequency distributions. In March and April, mature C. bairdi females were clearly either gravid or spent, and males had dark dorsal fins and were blue-black. $C$. cognatus were sexed by examination of the gonads. Gravid ovaries for both species were freeze-dried to constant weight, and the eggs broken apart and counted.

The analysis of covariance follows Brownlee (1965), but other regressions follow Sokal \& Rohlf (1969). The criterion for statistical significance is $\mathrm{p} \leqq 0.05$. Each regression of egg number or fish length on stream width was computed in the analysis of covariance using one point for each fish. The conclusions that there were significant linear regressions were verified by a more rigorous analysis in which the regression MS is tested over the population deviations MS, and the population deviations MS is tested over the within populations MS (Sokal \& Rohlf 1969, p. 439). The general conclusions were the same. 


\section{Results}

\section{Density}

Density in the 12 warmwater sites was lowest in the widest streams. The form of this relationship is not certain, but a linear regression is significant $\left(\mathrm{p}<0.05, \mathrm{r}^{2}=0.62\right)$. From preliminary observations I expected that sculpin densities would be low where rock bass were present. During sampling rock bass were observed at the five widest streams. These locations also had the five lowest densities of sculpins, a clearly nonrandom result (hypergeometric probability $\leqq 0.0013$ ). Though density declines in larger streams, it is not clear whether the relationship is gradual, or whether density drops abruptly where rock bass exist (Fig. 1).

In the Pigeon River drainage only $C$. bairdi were taken at the two widest sites and only $C$. cognatus at the six narrowest sites. Although large areas were fished at the two largest streams (1750 and $810 \mathrm{~m}^{2}$ ), only nine and two C. bairdi were taken and densities were clearly low $\left(1.0\right.$ and 0.5 per $\left.100 \mathrm{~m}^{2}\right)$. Trout were numerous at the five smallest streams but were also seen at the three largest. The density of $C$. cognatus was only 3.2 per $100 \mathrm{~m}^{2}$ at the largest

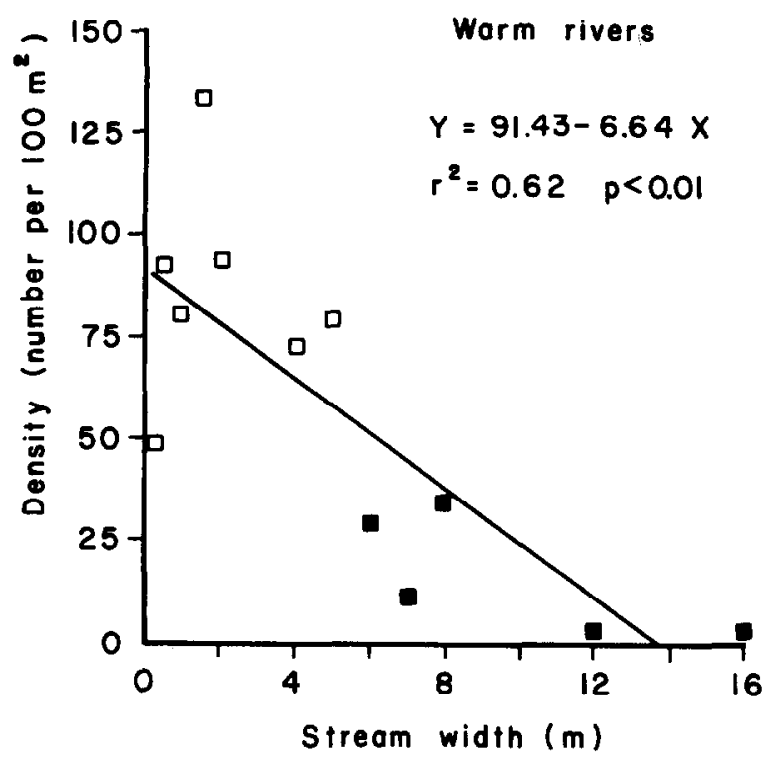

Fig. 1. Densities of Cottus bairdi in relation to stream width in warmwater streams in southeastern Michigan. Closed symbols are used for locations at which rock bass, a potential predator, were observed.

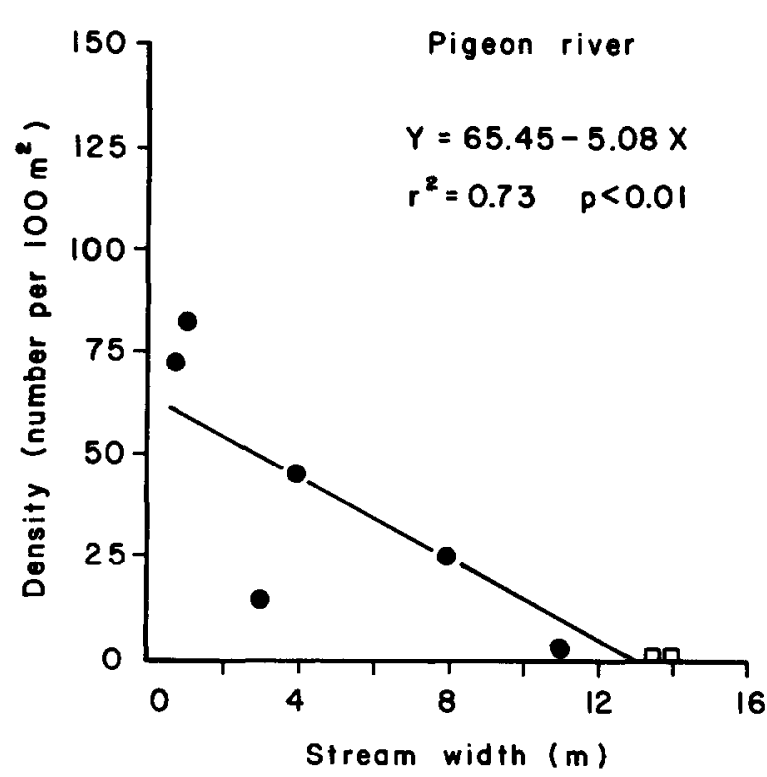

Fig. 2. Densities of sculpins in relation to stream width in the Pigeon River drainage in northern Michigan. Cottus cognatus (solid symbols) occurred in all but the two widest streams, where Cottus bairdi (open symbols) were collected. Predatory trout occur throughout the stream system.

stream widths, but reached 82 per $100 \mathrm{~m}^{2}$ where the stream was only one meter wide (Fig. 2). A linear regression again shows a significant decrease in sculpin density with increasing stream size if both species are pooled $\left(\mathrm{p}<0.05, \mathrm{r}^{2}=0.73\right)$ or if zero densities are used for $C$. cognatus at the largest two streams. If only the six locations where $C$. cognatus occurred are tested, the regression is only suggestive ( $\mathrm{p} \leqq 0.053, \mathrm{r}^{2}=0.65$ ). The relatively low density of sculpins that occurred where the stream was three meters wide obscures any trend in such a limited sample size. That location was beneath a closed canopy of conifers. At all other locations sampled the streams flowed through mixed conifer and hardwood forests.

\section{Growth}

One-year-old $C$. bairdi were taken at 11 of the 12 local warmwater streams. Mean total length of all one-year-olds increased significantly in wider streams, although there were also significant local deviations from the linear regression $(p<0.001$, Table 2). Only six of these, four males and two 
Table 2. Regressions of egg number (E) and sculpin total length (TL) against stream width (W). Sculpin lengths are measured in millimeters and stream widths in meters. Subscripts note sex (Male, Female, Immature) and age categories.

\section{Warm river systems}

$\begin{array}{lrrrr}\mathrm{E}_{\mathrm{F} .2} & =95.055+22.335 \mathrm{~W} & \mathrm{~N}-92 \mathrm{r}^{2}-0.50 & \mathrm{p} \leq 0.000 \\ \mathrm{E}_{\mathrm{F} .3}=159.590+37.343 \mathrm{~W} & 32 & 0.36 & 0.000 \\ \mathrm{TL}_{\mathrm{I} .1}=39.914+1.230 \mathrm{~W} & 202 & 0.20 & 0.000 \\ \mathrm{TL}_{\mathrm{F} .2}=61.503+1.664 \mathrm{~W} & 95 & 0.44 & 0.000 \\ \mathrm{TL}_{\mathrm{M} .2}=68.688+2.407 \mathrm{~W} & 86 & 0.47 & 0.000 \\ \mathrm{TL}_{\mathrm{F} .3}=75.965+1.737 \mathrm{~W} & 32 & 0.28 & 0.002 \\ \mathrm{TL}_{\mathrm{M} .3}=86.857+2.510 \mathrm{~W} & 29 & 0.24 & 0.007\end{array}$

Pigeon River system

$\begin{array}{rlrll}\mathrm{TL}_{\mathrm{l}, 1}=32.813+1.164 \mathrm{~W} & 122 & 0.32 & 0.000 \\ \mathrm{TL}_{\mathrm{F} .2}=60.687+1.004 \mathrm{~W} & 40 & 0.27 & 0.001 \\ \mathrm{TL}_{\mathrm{M} .2}=61.178+1.785 \mathrm{~W} & 32 & 0.38 & 0.000 \\ \mathrm{TL}_{\mathrm{F} .3}=81.182+0.468 \mathrm{~W} & 5 & 0.35 & 0.292 \\ \mathrm{TL}_{\mathrm{M} .3}=84.192+1.467 \mathrm{~W} & 4 & 0.10 & 0.676\end{array}$

females, had matured, so potentially confounding cffects of reproductive investment are minimal. These early maturing fish were the largest individuals in their cohorts.

All two-year-olds in local streams were sexually mature. Since adult $C$. hairdi are sexually dimorphic (Bailey 1952), the relationship between total length and stream width was determined for each sex. Analysis of covariance shows these twoyear-olds were significantly larger than one-yearolds and total length was greater in larger streams in each case (Table 2). The lengths of two-year-old females did not change as rapidly with stream size as did the lengths of two-year-old males ( $p \leqq 0.03$, Fig. 3, 4).

All local three-year-olds were sexually mature, but fewer were taken. They were found only in the small and mid-sized streams, possibly due to sampling error. The rclationship between sculpin length and stream width was significant ( $\mathrm{p} \leqq 0.001)$, and males were significantly larger than females (test of equal adjusted means $\mathrm{p} \leqq 0.001$ ).

In the Pigeon River system the growth of $C$. cognatus also varies with stream size. The general patterns are similar to those of warmwater $C$. bairdi: sculpins from the large streams are larger at any age and sexual dimorphism is evident by age two (Table 2), but sample sizes limit analysis of

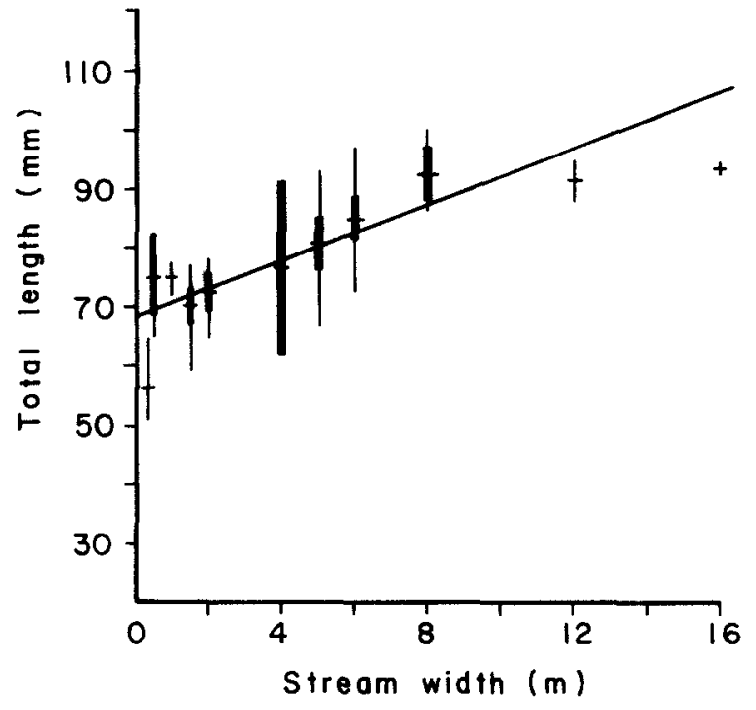

Fig. 3. The lengths of two-year-old male sculpins in warmwater streams. Lengths are significantly greater in larger streams $(p<0.001)$. The mean and range of individual lengths are shown for each population. Confidence intervals $(95 \%)$ are shown where sample size was 5 or more

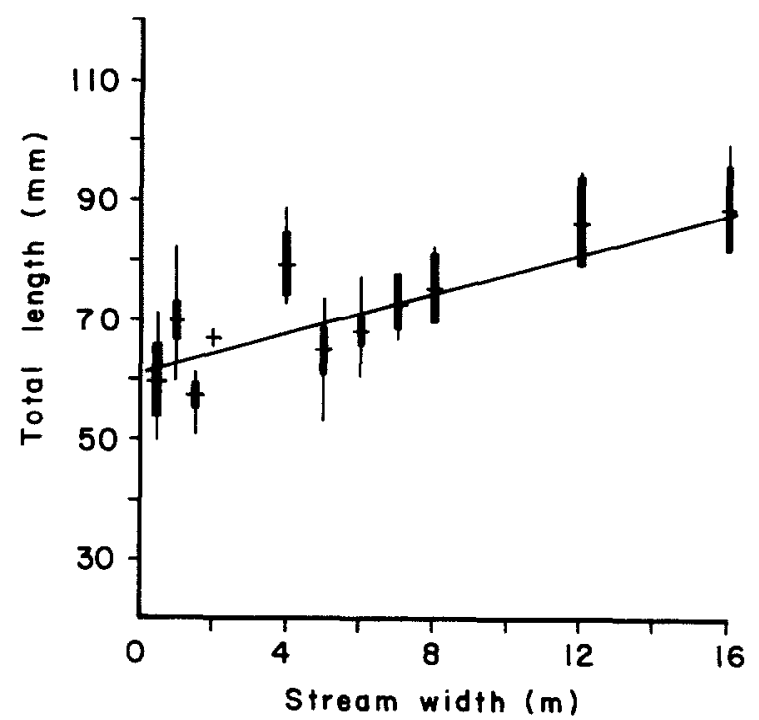

Fig. 4. The lengths of two-year-old Cemales in warmwater streams. Lengths are significantly greater in larger streams $(\mathrm{p}<0.001)$.

three- and four-year-old fish. Some two-year-olds were immature. These were from the narrower streams and were smaller than the average size of their cohort. 


\section{Fecundity}

Egg production is a function of female size in most fish. Sculpin fecundity would therefore be expected to increase with stream size, if only because females of any age tend to be longer in the larger streams. Egg counts from gravid females are a direct measure of fecundity. There were never more than four eggs or egg envelopes in the ovaries of any spent female, even in those taken within two days after the onset of spawning. In June samples from other streams all females were spent or immature, so the number of eggs counted represents the number of ripe, spawnable eggs. Egg resorption or incomplete egg release are uncommon among the large-egged forms of the genus Cottus (Hann 1927).

Ludwig \& Lange (1975) found a significant interaction of female length and age in determining the fecundity of $C$. cognatus in Wisconsin. Interactions with stream width cannot be incorporated in their model without loss of clarity. I used a stepwise linear regression with fecundity as a dependent variable, and female somatic wet weight, age, stream width and four simple interaction terms as independent variables. Female somatic weight and

Table 3. Egg numbers from gravid females in warm streams as a function of female somatic mass $(\mathrm{S}$, in $\mathrm{g})$, age $(\mathrm{A}$, in years) and the width of stream ( $\mathrm{W}$, in $\mathrm{m}$ ) where they were collected. Somatic mass and stream width are included in a stepwise multiple regression.

\begin{tabular}{lrlll}
\hline Source & df & MS & F & P \\
\hline Regression & 2 & $1.211 \times 10^{6}$ & 301.37 & 0.001 \\
Error & 123 & $4.018 \times 10^{3}$ & & \\
Total & 125 & & & \\
$\mathrm{r}^{2}=0.83$ & & & & \\
\hline Variable & Partial & Coefficient & P & \\
Constant & & -7.5338 & 0.508 & \\
S & 0.8697 & 48.1300 & 0.001 & \\
W & 0.2322 & 4.3292 & 0.009 & \\
& & & & \\
Remaining & Partial & & P & \\
A & -0.1290 & & 0.153 & \\
A $\times$ W & 0.0058 & & 0.949 & \\
S $\times$ W & -0.0228 & & 0.802 & \\
S $\times$ A & -0.0397 & & 0.662 & \\
S $\times$ A $\times$ W & 0.0560 & & 0.537 & \\
\hline
\end{tabular}

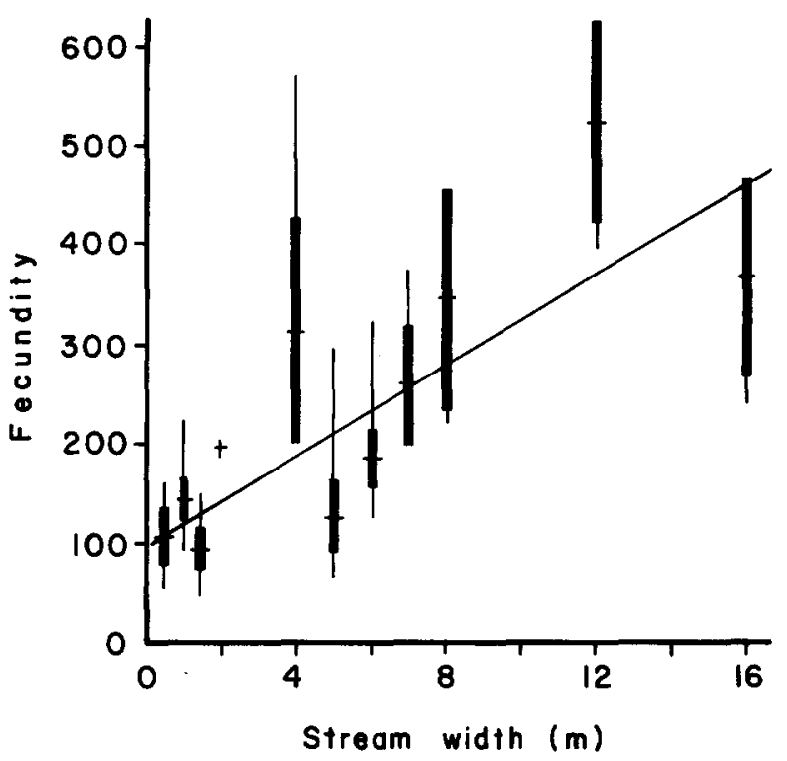

Fig. 5. The number of eggs carried by gravid two-year-old females in warmwater streams. Females in larger streams produce significantly more eggs than females of similar size in small streams (see text).

stream width enter as significant terms (Table 3). Fecundity is greater in larger streams (Fig. 5, Table 2,3 ) where females of any age are larger, because fecundity increases with body size and because size-specific fecundity is greater. In a $0.5 \mathrm{~m}$ wide stream, two-year-old females average $60 \mathrm{~mm}$ total length, $2.0 \mathrm{~g}$ somatic body mass, and carry 105 eggs. In a $12 \mathrm{~m}$ wide stream, two-year-old females average $86 \mathrm{~mm}$ total length, $8.5 \mathrm{~g}$ somatic body mass and carry 523 eggs. Unfortunately, many of the $C$. cognatus spawned before collections were made in the Pigeon River, so the analysis of egg production could not be duplicated.

\section{Discussion}

\section{Does stream size change population regulation?}

I hypothesized that interactions with predators, competitors, or prey change with stream size and alter survivorship, growth and reproduction. Density, growth rates and fecundity all show significant regressions against stream width, demonstrating that the factors regulating populations do change with stream size. Further, the occurrence of similar 
patterns in cold and warm systems and within each warmwater tributary suggests the patterns are persistent and may have a common cause.

Predation is a likely cause of low sculpin density in large streams. Sculpins are a small but regular portion of the diet of brook charr (Salvelinus fontinalis) in Hunt Creek in Michigan (G. R. Alexander personal communication). Smallmouth bass (Micropterus dolomieui) and many salmonids eat sculpins in other systems (Scott \& Crossman 1973, Moyle 1977). Abilities of salmonids and centrarchids to catch benthic prey depend upon substrate size or complexity (Ware 1972, Stein \& Magnuson 1976, Crowder \& Cooper 1982), so risk should change with microhabitat and stream size. Laboratory experiments corroborate this model for sculpins: young sculpins are most vulnerable to rock bass in deep water and on simple substrates; sculpins prefer complex substrates and deep water but shift into shallow water when rock bass $(\mathrm{Am}$ bloplites rupestris) are added (Anderson 1983).

The greater size of young sculpins surviving in larger streams is not attributable solely to selective predation on slower growing individuals, since the average size in large streams exceeds the maximum in much smaller streams. A change in food availability or conversion efficiency with stream size must also occur.

If sculpin growth is density-dependent, a gradient in risk of predation could explain why growth is rapid where density is low, and why the patterns persist in different tributaries. This simple explanation predicts that growth rates are density-dependent. Alternatively, a gradient in resource productivity could change growth rates, since sculpin growth rates depend upon insect density in laboratory streams (Brocksen et al. 1968). Field experiments show growth in enclosures is density-dependent but also changes with stream size (Anderson 1983).

Complex regulatory changes through time and space may be common. Sculpins may compete with young salmonids (Brocksen et al. 1968) and sometimes prey on them, but sculpins are eaten by larger salmonids (reviewed by Moyle 1977). The importance of interactions between sculpins and their predators' young has not been established in con- trolled field experiments. Finger (1982) concluded both predation and competition with other cottids restricted density and habitat use of $C$. perplexus in large Oregon streams.

Terrestrial predators may consume sculpins or larger fish that prey on sculpins. Several predators select large trout in Michigan streams (Alexander 1979), but their influence on sculpins has not been determined. Power (1983) presents evidence that terrestrial predators are important in a small Panamanian stream, but prey size is critical. She reports that algae-grazing catfishes are restricted to pools as adults because of bird and mammal predation, though algae are more abundant in riffles.

Chronic or fluctuating physical, chemical or thermal conditions are unlikely to be the sole cause of low sculpin density in these streams. If low density in large streams resulted from chronic conditions, sublethal effects upon reproduction and growth would be expected (Fry 1947). However, individual growth rates are higher even among juveniles, and adults have greater fecundities. Growth rate may increase with temperature until near the thermal lethal limit if rations and oxygen levels are high (Brett et al. 1969, McCormick et al. 1972), but the upper sections of the Pigeon River where I sampled do not appear to reach lethal temperatures for C. cognatus (Knutilla 1967, Otto $\&$ Rice 1977). Moreover, in the warm streams juveniles continue to feed and grow during late summer temperature maxima. Fluctuations of conditions in large streams may occasionally cause mortality, but the relative stability of conditions in most large streams supported the hypothesis that episodes of mortality are more frequent in smaller headwaters (Horwitz 1978, Schlosser 1982, but see Smith 1981, Baltz et al. 1982, Minshall et al. 1983).

The changes in regulatory mechanisms depend upon the species examined and the nature of environmental fluctuations. The consistency of these observations in stable Michigan streams contrasts with the transient density cline noted by Baltz et al. (1982) in C. gulosus recolonizing a warm reach of California stream where populations had been extirpated during a summer drought. They showed that microhabitat utilization by dace was influenced by sculpin density and that the interaction 
was mediated by a gradient in temperature extremes.

When the relative abundances of microhabitats, predators or prey changes with stream size, local regions good for growth of one size class may be poor for survivorship of another in spite of some ability to choose microhabitats. This might account for the opposite trends in sculpin density and fecundity and is probably the ultimate cause of migration in stream fish which are larger or more mobile.

\section{Local regulation}

The hypothesis that unique local conditions influence regulatory mechanisms must also be accepted because there were significant local deviations about regressions of growth and fecundity on stream width. A survey of 10 pairs of streams in the northwestern United States by Hawkins et al. (1983) indicated several factors are important. Their study showed that sculpin density was correlated with substrate composition and that sculpins were more abundant in streams without riparian shading. These factors influence insect productivity. They change locally and along a stream continuum.

\section{Extirpation/recolonization hypothesis}

The extirpation/recolonization model can be rejected for sculpins because it fails to correctly predict trends in density, growth rate, or fecundity over a range of stream sizes. The smallest streams would be expected to support faster growth if interor intra-specific competitive release occurred. Introducing simple density dependence does not improve the model's predictive capability because growth rate is consistently lower in smaller streams.

The pattern of sculpin density is the reverse of that thought to occur just after an extirpation event continuous throughout some series of smaller streams. If episodes of mortality occur, the intervals between episodes may be long relative to the recolonization time. Alternatively, the mechanisms which structure population growth are strongly dependent upon stream size and density, so that stocks rapidly approach a characteristic density once colonization occurs. In small streams high densities may be attainable by species resistent to episodic mortality. Matthews \& Styron (1981) found that Etheostoma flabellare from headwaters were more tolerant of environmental extremes than conspecifics from the mainstream. A severe flash flood in Fleming Creek in 1979 caused little displacement of marked sculpins and growth was similar to that in two subsequent years (Anderson 1983).

Regular changes in fish diversity and species richness provided indirect evidence for the extirpation/recolonization model (Whiteside \& McNatt 1972, Horwitz 1978, Smith 1981). However, environmental fluctuations may alter movements and biological interactions rather than directly causing extirpation. Movements of smallmouth bass were greater in a stream with greater discharge fluctuation (Fajen 1962). The speeds of recolonizations reported by Larimore ct al. (1959) and Harrel et al. (1967) suggest that fish rapidly regain their former distribution, beyond which movements are reduced, so other factors generally limit headwater distributions.

\section{Habitat distribution hypothesis}

These data do not support the hypothesis that sculpins are habitat specialists limited by the distribution of some critical microhabitat. Densities of both species decrease downstream as predicted for fish limited by shallow rocky areas or spawning cavities (Balon 1975), but the correspondence to the local density of some particular, purportedly limiting habitat is questionable. Sculpins spawn in a variety of cavities (Koster 1937, Van Vliet 1964, Ludwig \& Norden 1969, personal observations). Both $C$. bairdi and $C$. cognatus exist in habitats ranging from rocky riffles, to sandy streams, to the deep bottoms of large lakes (Scott \& Crossman 1973).

Another prediction can be tested. If sculpins are habitat specialists, their demographic structures within patches of suitable habitat should be similar at different localities. There should be no systematic changes in growth rates or fecundities either 
between locations or with stream size. Since sculpins in larger streams have faster growth rates and higher fecundities, it is clear suitable microhabitats change qualitatively with stream size.

\section{Conclusions}

Clines in sculpin density, growth and fecundity support the hypothesis that biological interactions change regularly with stream size. There are local deviations about the general trends but the patterns appear to be persistent. The data do not support the hypotheses that sculpins are limited by microhabitat availability or by extirpation/recolonization processes in headwaters.

The densities of $C$. bairdi in warm streams and C. cognatus in cold streams are lower in large streams than in small streams. Growth rates are faster in the larger streams. Egg production is as much as five times higher in the larger streams because females are larger and because size-specific fecundity is greater. These patterns suggest that predation reduces sculpin density in larger streams and that growth is density-dependent. This explanation predicts that mortality rates are greater on simple substrates, in deep water and where piscivorous fish are present. Growth and fecundity are influenced by changes in productivity both locally and along a stream size gradient. A combination of comparative and experimental studies can rigorously test theories about how the mechanisms structuring populations and communities change along gradients in streams (Vannote et al. 1980, Newbold et al. 1982, Schlosser 1982).

\section{Acknowledgements}

I thank Gerald Smith, James Diana, Alvin Jensen, John Vandermeer, Jeri Glick and two anonymous reviewers for criticizing earlier drafts of this text. This paper is based on a chapter of a dissertation submitted to the University of Michigan. I received support from an N.S.F Graduate Fellowship, a Rackham Dissertation Grant, a Biological Sciences Block Grant, a Walker-Hinsdale Fellowship and the Theodore Roosevelt Memorial Fund. Tom Rhuelmann and Noah Belanger each assisted me for one summer and deserve special thanks. Manuscript preparation was supported by contract DE-AC09-SR00-819 between the University of Georgia and the U.S. Department of Energy.

\section{References cited}

Alexander, G.R. 1979. Predators of fish in coldwater streams. pp. 153-170. In: H. Clepper (ed.) Predator-Prey Systems in Fishcries Management, Sport Fishing Institute, Washington, D.C.

Alstad, D.N. 1982. Current speed and filtration rate link caddisfly phylogeny and distributional patterns on a stream gradient. Science 216: 533-534.

Anderson, C.S. 1983. The influence of stream size on sculpin population dynamics. Ph.D. Thesis, The University of Michigan, Ann Arbor. $161 \mathrm{pp}$.

Bailey, J.E. 1952. Life history and ecology of the sculpin Cottus bairdi punctulatus in southwestern Montana. Copeia 1952: 243-254.

Balon, E.K. 1975. Reproductive guilds of fishes: a proposal and definition. J. Fish. Res. Board Can. 32: 821-864.

Baltz, D.M., P.B. Moyle \& N.J. Knight. 1982. Competitive interactions between benthic stream fishes, riffle sculpin, Cottus gulosus, and speckled dace, Rhinichthys osculus. Can. J. Fish. Aquat. Sci. 39: 1502-1511.

Brett, J.R., J.E. Shelbourn \& C.T. Shoop. 1969. Growth rate and body composition of fingerling sockeye salmon, Oncorhynchus nerka, in relation to temperature and ration size. J. Fish. Res. Board Can. 26: 2363-2394.

Brocksen, R.W., G.E. Davis \& C.E. Warren. 1968. Competition, food consumption, and production of sculpins and trout in laboratory stream communities. J. Wildl. Mgmt. 32: $51-75$

Brown, L. \& J.F. Downhower. 1982. Summer movements of mottled sculpins, Cottus bairdi (Pisces: Cottidae). Copeia 1982: 450-453.

Brownlee, K.A. 1965. Statistical theory and methodology in science and engineering. John Wiley and Sons, New York. $590 \mathrm{pp}$.

Crowder, L.B. \& W.E. Cooper. 1982. Habitat structural complexity and the interaction between bluegills and their prey. Ecology 63: 1802-1813.

Fajen, O.F. 1962. The influence of stream stability on the homing behavior in two smallmouth bass populations. Trans. Amer. Fish. Soc. 91:346-349.

Finger, T.R. 1982. Interactive segregation among three species of sculpins (Cottus). Copeia 1982: 680-694.

Fry, F.E.J. 1947. Effects of the environment on animal activity, Univ. Toronto Studies Biol. Ser. 55: 1-62.

Gorman, O.I. \& J.R. Karr. 1978. Habitat structure and stream 
fish communities. Ecology 59: 507-515.

Hann, H.W. 1927. The history of the germ cells of Cottus bairdi Girard. J. Morph. Physiol. 43: 427-497.

Harrel, R.C., B.J. Davis \& T.C. Dorris. 1967. Stream order and species diversity of fishes in an intermittent Oklahoma stream. Amer. Midl. Nat. 78: 428-436.

Hawkins, C.P., M.L. Murphy, N.H. Anderson \& M.A. Wilzbach. 1983. Density of fish and salamanders in relation to riparian canopy and physical habitat in streams of the northwestern United States. Can. J. Fish. Aquat. Sci. 40:11731185.

Horwitz, R.J. 1978. Temporal variability patterns and the distributional patterns of stream fishes. Ecol. Monogr. 48: 307321.

Knutilla, R.L. 1967. Flow characteristics of Michigan streams. U.S.G.S., Water Resource Division, Lansing, Michigan. $337 \mathrm{pp}$.

Koster, W.J. 1937. The food of sculpins (Cottidae) in central New York. Trans. Amer. Fish. Soc. 66:374-382.

Larimore, R.W., W.F. Childers \& C. Heckrotte. 1959. Destruction and re-establishment of stream fish and invertebrates affected by drought. Trans. Amer. Fish. Soc. 88: 261-285.

Ludwig, G.M. \& E.L. Lange. 1975. The relationship of length, age, and age-length interaction to the fecundity of the northern mottled sculpin, Cotus b. bairdi. Trans. Amer. Fish. Soc. 104: 64-67.

Ludwig, G.M. \& C.R. Norden. 1969. Age, growth and reproduction of the northern mottled sculpin (Cottus bairdi bairdi) in Mt. Vernon Creek, Wisconsin. Milwaukee Public Museum, Occ. Pap. Nat. I list. 2: 1-67.

Mahon, R. 1980. Accuracy of catch-effort methods for estimating fish density and biomass in streams. Env. Biol. Fish. 5: 343-360.

Mason, J.C. \& S. Machidori. 1976. Populations of sympatric sculpins, Cottus aleuticus and Cottus asper, in four adjacent salmon-producing coastal streams on Vancouver Island, B.C. U.S. Fish. Bull. 74: 131-141.

Matthews, W.J. \& J.T. Styron, Jr. 1981. Tolerance of headwater vs. mainstream fishes for abrupt physicochemical changes. Amer. Midl. Nat. 105: 149-158.

McCormick, J.H., K.E.F. Hokanson \& B.R. Jones. 1972. Effects of temperature on growth and survival of young brook trout, Salvelinus fontinalis. J. Fish. Res. Board Can. 29: 11071112.

Minshall, G.W., R.C. Peterson, K.W. Cummins, T.L. Bott, J.R. Sedell, C.E. Cushing \& R.L. Vannote. 1983. Interbiome comparison of stream ecosystem dynamics. Ecol. Monogr. 53: $1-25$.

Moyle, P.B. 1977. In defense of sculpins. Fisheries 2: 20-23.

Newbold, J.D., R.V. O'Neill, J.W. Elwood \& W. van Winkle.
1982. Nutrient spiralling in streams: implications for nutrient limitation and invertebrate activity. Amer. Nat. 120:628-652.

Otto, R.G. \& J.O. Rice. 1977. Responses of a freshwater sculpin (Cottus cognatus gracilis) to temperature. Trans. Amer. Fish. Soc. 106: 89-94.

Power, M.E. 1983. Grazing responses to tropical freshwater fishes to different scales of variation in their food. Env. Biol. Fish. 9: 103-115.

Schlosser, I.J. 1982. Fish community structure and function along two habitat gradients in a headwater stream. Ecol. Monogr. 52:395-414.

Scott, W.B. \& E.J. Crossman. 1973. Freshwater fishes of Canada. Físheries Research Board of Canada Bull. 184: 1-966.

Sheldon, A.L. 1968. Species diversity and longitudinal succession in stream fishes. Ecology 49: 193-198.

Shelford, V.E. 1911. Ecological succession. I. Stream fishes and the method of physingraphic analysis. Biological Bulletin 21: 9-35.

Smith, G.R. 1981. Effects of habitat size on species richness and adult body sizes of desert fishes. pp. 125-171. In: R.J. Naiman \& D.L. Soltz (ed.) Fishes in North American Deserts, John Wiley and Sons, New York.

Smith, G.R., J.N. Taylor \& T.W. Grimshaw. 1981. Ecological survey of fishes in the Raisin River drainage, Michigan. Michigan Academician 13: 275-305.

Sokal, R.R. \& F.J. Rohlf. 1969. Biometry. W.H. Freeman, San Francisco. $776 \mathrm{pp}$.

Stalnaker, C.B. 1979. The use of habitat structure preferenda for establishing flow regimes necessary for maintenance of fish habitat. pp. 321-338. In: J.V. Ward \& J.A. Stanford (ed.) The Ecology of Regulated Streams, Plenum Press, New York.

Stein, R.A. \& J.J. Magnuson. 1976. Behavioral response of crayfish to a fish predator. Ecology 57: 751-761.

Vannote, R.L., G.W. Minshall, K.W. Cummins, J.R. Sedell \& C.E. Cushing. 1980. The river continuum concept. Can. J. Fish. Aquat. Sci. 37: 130-137.

Van Vliet, W.H. 1964. An ecological study of Cottus cognatus Richardson in northern Saskatchewan. M.A. Thesis, University of Saskatchewan, Saskatoon. $155 \mathrm{pp}$.

Ware, D.M. 1972. Predation by rainbow trout (Salmo gairdneri): the influence of hunger, prey density, and prey size. J. Fish. Res. Board Can. 29: 1193-1201.

Whiteside, B.G. \& R.M. McNatt. 1972. Fish species diversity in relation to stream order and physicochemical conditions in the Plum Creek drainage basin. Amer. Midl. Nat. 88: 90-101.

Zippin, C. 1956. An evaluation of the removal method of estimating animal populations. Biometrics 12:163-189.

Received 24.10.1983 Accepted 27.5.1984. 